\title{
A IDENTIDADE ÉTNICA DOS JOVENS BRASILEIROS NO JAPÃO
}

Eunice Akemi Ishikawa ${ }^{1}$

Resumo: A vinda dos nikkeis brasileiros ao Japão, o chamado movimento dekassegui, causou uma mudança no trajeto migratório do Japão ao Brasil, e uma reavaliação da identidade étnica como "japonês". Muitos nikkeis são considerados japoneses pela sociedade brasileira e muitos se consideram como tal devido às influências sociais e culturais recebidas dentro da sociedade japonesa no Brasil. Porém, no Japão esses nikkeis se chocam ao serem recebidos como estrangeiros e ter sua identidade "japonesa" rejeitada. Após 25 anos desde o início deste movimento, os filhos dos brasileiros no Japão passam por experiências semelhantes aos seus ancestrais no Brasil, uma vez que no Japão, estes passam a se consider mais japoneses que brasileiros.

Palavras-chave: Nikkei; identidade; etnia; capital cultural; dekassegui.

Abstract: The dekassegui movement of Japanese-Brazilians from Brazil to Japan caused changes in the migration trajectory from Japan to Brazil, and the need to rethink the concept of Japanese ethnic identity created in Brazil. Many Japanese-Brazilians consider themselves to be "Japanese" as they are considered by Brazilian society. However, in Japan they are received as foreigners, despite their Japanese background. 25 years since moving to Japan, their children, born and raised in Japanese society, have a "Brazilian" ethnic identity experience that is similar to what their ancestors faced in Brazil.

Keywords: Nikkei; identity; ethnic; cultural capital; dekassegui.

1. Professora do Departamento de Cultura Internacional da Universidade de Arte e Cultura de Shizuoka (SUAC), Hamamatsu, Japão; eunice@suac.ac.jp 


\section{Introdução}

A maioria dos jovens brasileiros que reside atualmente no Japão são filhos de brasileiros que vieram ao Japão no início dos anos de 1990, no fenômeno chamado "dekassegui". Dentre estes jovens muitos são nascidos no Japão e se consideram "japoneses", tendo o Brasil apenas como o país de origem de seus pais. Muitos destes jovens que nasceram no Japão ou vieram ainda pequenos foram imersos nas escolas japonesas, e consequentemente adquiriram a língua e cultura japonesa como parte de sua identidade. Mas como será que eles se sentem, "japoneses" ou "brasileiros"? Como é o dia-a-dia destes jovens que vivem em uma dupla realidade, a japonesa fora de casa e a brasileira no ambiente familiar?

A história do movimento migratório dos brasileiros ao Japão teve início em meados dos anos de 1980, quando já se verificava a vinda de alguns brasileiros descendentes de japoneses com o propósito de trabalharem no país. Muitos destes vinham com visto de turista, e outros por possuírem a nacionalidade japonesa, entravam no país como japoneses. A partir de 1990, devido a modificação parcial da lei referente à entrada de estrangeiros e refugiados no Japão, o qual facilitou a entrada de descendentes de japoneses de segunda e terceira gerações, o número de brasileiros residentes no Japão aumentou gradativamente até 2008, atingindo o total de 312.582 (Ver gráfico 1).

Os descendentes de segunda geração passaram a entrar no Japão com o visto de "cônjuge ou filhos de japoneses" e os de terceira geração com o visto de "residente", vistos nos quais não há restrição em relação a atividades remuneradas durante sua permanência no Japão. Vale lembrar que no Japão não há uma qualificação de permanência que permita o trabalho não-qualificado para estrangeiros, e no caso de descendentes de japoneses, estes são considerados apenas "parentes" de japoneses que estão no Japão com o propósito de visita familiar, e que exercem atividades remuneradas por tempo limitado.

Só a partir de 2008, com os efeitos da crise econômica mundial, o qual afetou diretamente os trabalhadores brasileiros no Japão com o desemprego, o número de brasileiros residentes cai para 175.410, sendo a quarta maior população de estrangeiros no Japão, precedidos pelos chineses com 650 mil, pelos coreanos com 500 mil e pelos filipinos, com 217 mil. Porém, apesar da população ter diminuído 40\%, o número de brasileiros com visto permanente aumentou para 111.077 , ou seja $60 \%$ dos brasileiros residentes no Japão possui o visto que lhe dá garantia de permanência contínua no país, independentemente de sua estabilidade no trabalho, fluência na língua japonesa ou intenção de retorno ao Brasil. 
Tabela 1. População de brasileiros no Japão (1985 - 1993)

\begin{tabular}{|c|c|c|c|c|c|c|c|c|}
\hline & $\mathbf{1 9 8 5}$ & $\mathbf{1 9 8 7}$ & $\mathbf{1 9 8 8}$ & $\mathbf{1 9 8 9}$ & $\mathbf{1 9 9 0}$ & $\mathbf{1 9 9 1}$ & $\mathbf{1 9 9 2}$ & $\mathbf{1 9 9 3}$ \\
\hline População & 1.900 & 2.250 & 4.159 & 14.528 & 56.429 & 119.333 & 147.803 & 154.650 \\
\hline
\end{tabular}

Tabela 2. População de brasileiros no Japão e respectivos vistos (1994 - 2014)

\begin{tabular}{|l|c|c|c|c|c|c|}
\hline & $\mathbf{1 9 9 4}$ & $\mathbf{2 0 0 0}$ & $\mathbf{2 0 0 5}$ & $\mathbf{2 0 0 7}$ & $\mathbf{2 0 0 8}$ & $\mathbf{2 0 1 4}$ \\
\hline População & 159.619 & 254.394 & 302.080 & 316.967 & 312.582 & 175.410 \\
\hline Cônjuge ou filho de japonês & 95.139 & 101.623 & 78.851 & 67.472 & 58.445 & 15.565 \\
\hline Residente & 59.280 & 137.649 & 153.185 & 148.528 & 137.005 & 44.559 \\
\hline Permanente & 373 & 9.062 & 63.643 & 94.358 & 110.267 & 111.077 \\
\hline
\end{tabular}

Fonte: Japan Immigration Association and Ministry of Justice of Japan, ZAIRYU GAIKOKUJIN TOUKEI 1986 a 2015.

\section{Gráfico 1- População de brasileiros no Japão 1985 - 2014}

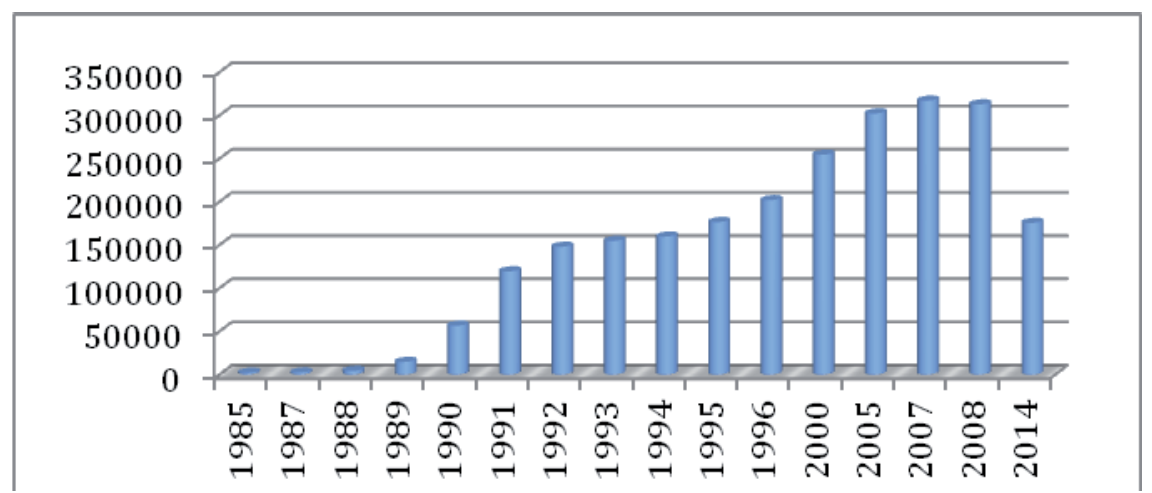

Fonte: Japan Immigration Association and Ministry of Justice of Japan, ZAIRYU GAIKOKUJIN TOUKEI 1986 a 2015.

Em 2014, o número de jovens brasileiros (nacionalidade brasileira) de 0 a 15 anos de idade residentes no Japão é de 33,065, o que representa $19 \%$ da população brasileira $(175,410)$ no país.

A maioria delas, frequenta escolas japonesas, enquanto algumas optam por escolas brasileiras, onde recebem o ensino em português com o currículo reconhecido pelo Ministério da Educação do Brasil. Porém, tanto nas escolas japonesas como nas escolas 
brasileiras, as crianças enfrentam diversos problemas de aprendizagem e adaptação social e cultural no Japão (ISHIKAWA, 2012).

Ao contrário da experiência vivida pelos descendentes de japoneses no Brasil, no Japão os crianças e jovens brasileiros enfrentam o dilema de se autoidentificarem como brasileiros, uma vez que sua experiência de vida é basicamente no Japão.

Neste artigo será discutido o processo de assimilação e aculturação destes jovens na sociedade japonesa, comparando com a história e experiências na formação da identidade étnica dos nikkeis no Brasil. Será apresentado também casos de jovens, filhos de trabalhadores brasileiros que ingressaram em universidades japonesas, para relatar suas experiências nas escolas e no ambiente familiar brasileiro no Japão.

\section{Ser "japonês" no Brasil}

O termo etnia proporciona-nos diversas interpretações, como referentes à religião, à raça, à cultura, à nacionalidade, à profissão, à posição social, à língua, entre outros. Anteriormente estes conceitos referiam-se principalmente aos grupos de imigrantes e aos grupos minoritários, porém na sociedade moderna passa a abranger diversos campos de interpretações (GLAZER, 1975). Como exemplos podemos citar a discriminação racial contra os negros nos Estados Unidos e o problema referente à língua francesa e inglesa utilizada no Canadá. Estes dois itens podem ser considerados como problemas étnicos, porém não podemos compará-los em um mesmo parâmetro.

Quanto à identidade, este pode ser entendido como consciência (ou sentimento) de um indivíduo que o leva a incluir-se a um determinado grupo étnico. Esta identificação com o grupo, segundo Reitz, não se encontra diretamente ligado ao processo de aculturação (REITZ, 1980). Ou seja, mesmo que dois ou mais grupos étnicos estejam aculturados em um mesmo nível social em uma determinada sociedade, observa-se diferenças quanto ao grau de preservacão de cada grupo étnico (FUJITA; O'BRIEN, 1991). Assim, para a análise da preservação de grupos étnicos de imigrantes por exemplo, é necessário a análise detalhada referente à época e condições históricas da imigração, à raça, à religião, à língua, entre outros, do grupo de imigrantes e da sociedade receptora. Por exemplo, na pesquisa de Fujita, ele analisa os nikkeis americanos e constata que apesar de um avançado grau de aculturação estrutural (organizações, clubes, moradia, profissão) por parte dos mesmos na sociedade norte-americana, eles ainda preservam o seu grupo étnico, onde muitos participam ativamente (FUJITA; O’BRIEN, 1991).

O fenômeno dekassegui dos nikkeis brasileiros, ou seja o movimento inverso dos imigrantes japoneses no Brasil, cujo objetivo era a estada temporária no Japão com intenção de retorno ao Brasil, proporcionou aos nikkeis o contato direto com a sociedade japonesa, possibilitando-lhes a comparação da sociedade japonesa atual com a sociedade nikkei no Brasil, onde ainda hoje preserva-se a "cultura japonesa idealizada". No Japão, os nikkeis brasileiros tem um choque cultural, pois a cultura "japonesa" que foi transmitida no Brasil é diferente da japonesa no Japão atual. 
O primeiro choque é saber que no Japão os nikkeis são considerados estrangeiros, e mesmo aqueles que falam o idioma japonês não são considerados como japoneses. Por exemplo, no Brasil as características culturais "japonesas" e as físicas eram fatores suficientes para serem considerados japoneses, o que fazia com que eles próprios se identificassem como tal, fortalecendo a identidade étnica japonesa. Porém, no Japão suas características culturais brasileiras são fatores relevantes para diferenciar um nikkei brasileiro de um japonês, e se considerarmos as diferenças da cultura "japonesa" do Brasil e a japonesa do Japão, a diferença entre um nikkei e um japonês torna-se ainda maior. A identidade do nikkei brasileiro tem se modificado conforme a época, geração, ambiente social em que vive, formação educacional, entre outros. Aqui focaliza-se sobretudo o movimento internacional de sua mão-de-obra ao Japão. Fato recente que tem influenciado com grande intensidade a comunidade nipo-brasileira, tanto no Brasil como no Japão.

A formação da identidade étnica dos nikkeis brasileiros tem simultaneamente grande influência da sociedade brasileira e da educação "japonesa" recebida dentro de suas casas no Brasil. Aqui, abordaremos a identidade étnica dos nikkeis brasileiros tendo como referência o conceito de cultura, e para sua análise adotaremos os conceitos de "capital cultural" e "habitus"(BORDIEU, 1984).

O termo "capital cultural" refere-se ao capital próprio ou adquirido de um agente dentro de um ambiente cultural (MIYAJIMA, 1994). No caso do capital cultural dos nikkeis brasileiros, podemos dizer que é formado pela educação transmitida pelos pais e/ou avós japoneses que emigraram ao Brasil, e que consciente ou inconscientemente tem sido incorporada às suas características culturais. Além dos aspectos culturais, não podemos deixar de considerar o aspecto físico dos nikkeis, que com suas características orientais, são facilmente distinguidos dentro da sociedade brasileira. Assim, a maioria dos nikkeis, mesmo aqueles que nunca aprenderam uma só palavra em japonês ou nunca tenham comido um prato japonês, são chamados de "japonês" no Brasil (MAEYAMA, 1996). Chamamos de habitus os costumes, pensamentos, ações e tendências (atitudes, religião, moral, etc) que um indivíduo adquire no meio em que vive, e que faz com que um grupo desses indivíduos com características semelhantes forme uma comunidade, uma sociedade, um país, etc. Frisamos aqui, que o habitus é um conceito dinâmico, que tende a modificar-se conforme as mudanças que ocorrem no ambiente. Estes fatores internos e externos tem contribuido para a formação e preservação da cultura "japonesa" no Brasil. Por exemplo, hoje ainda é comum um nikkei frequentar clubes culturais nikkeis (de dança, de música, de senhoras, de jovens, de províncias, etc.), e muitos destes casam-se com nikkeis. A estatística do Centro Cultural Brasil-Japão/1988, revela que no Brasil 54\% dos nikkeis são casados com nikkeis.

Segundo Maeyama, o imigrante japonês se conscientizou como um "japonês" no Brasil (MAEYAMA, 1982). Ou seja, nas plantações de café no Brasil, o imigrante japonês teve os primeiros contatos com imigrantes italianos, alemães, espanhóis, entre outros e com os negros, sendo que alí os imigrantes japoneses eram especificados como "japoneses". 
Nestas circunstâncias, a identidade do imigrante japonês foi se fortalecendo, principalmente para se distinguir dos outros. Porém esta identidade como "japonês" foi se modificando com o tempo e com as novas circunstâncias de vida no Brasil. A sua identidade foi se transformando aos poucos de japonês para "brasileiro". Segundo Maeyama, os imigrantes japoneses no Brasil passaram por 3 estágios de adaptação, sendo: 1) Primeira Estratégia de Dekassegui, 2) Segunda Estratégia de Dekassegui e 3) Estratégia de Permanência Definitiva. Nestes três estágios de adaptação, Maeyama descreve a mudança de identidade do imigrante japonês, que no primeiro estágio o imigrante se identificava como um japonês que permanece por um curto período no Brasil, e no final do terceiro período o imigrante japonês e seus descendentes passam a se identificar como "brasileiros". Porém, um fator a ser frisado aqui, é que a emigração japonesa para o Brasil continua, em pequena escala, até o início dos anos 70, o que significa que durante todo o período sempre houve novos imigrantes recém-chegados no Brasil, fazendo com que sempre houvesse a presença de japoneses natos entre os nikkeis, personagens importantes que serviram de intermediários entre a cultura japonesa (do Japão) e os nikkeis no Brasil. Ou seja, a identidade dos nikkeis brasileiros teve influências durante todo este período da imigração, que ora se identificavam como "japoneses" ora como "brasileiros", dependendo da situação.

Os nikkeis herdaram uma cultura em que a imagem do Japão é idealizada pelos imigrantes japoneses no Brasil, onde Japão ou japonês são sinônimos de "honestidade", "lealdade" e "perseverança", qualidades estas que os nikkeis recebem como sendo uma cultura japonesa, e que por sua vez, procuram evidenciar dentro da sociedade brasileira.

\section{Formação do grupo étnico dos nikkeis no Brasil}

Os nikkeis são aqueles que herdaram a educação, os costumes e a cultura japonesa diretamente dos imigrantes japoneses no Brasil (neste caso de seus pais e/ou avós), e que dentro da sociedade brasileira onde nasceram e vivem, procuram atender às expectativas que lhe são posicionadas, por um lado pelas suas famílias e pelo grupo étnico nipo-brasileiro, e por outro pela realidade da sociedade brasileira.

Os primeiros imigrantes japoneses para o Brasil tinham como objetivo retornar ao Japão após um curto período de trabalho. Assim, a educação dos filhos era direcionada para quando estes retornassem ao Japão, ou seja, os filhos eram educados como japoneses, e em muitos casos como japoneses "exemplares". Porém com o passar dos anos, o objetivo de retornar ao Japão vai modificando-se devido a vários fatores, fortalecendo a possibilidade dos imigrantes japoneses e nikkeis de permanecerem permanentemente no Brasil. Dentro desta mudança de condições, verifica-se alguns movimentos entre os nikkeis para concretizar a sua posicão dentro da sociedade brasileira. Como exemplo, podemos citar a fundacão da Cooperativa Bratac (Cooperativa de Colonização no Brasil) em 1934. 
Esta cooperativa tinha como objetivo coordenar e incentivar os agricultores japoneses e/ou nikkeis residentes nos quatro maiores centros da colônia japonesa no estado de São Paulo (Aliança, Tietê, Bastos e Três Barras) a permanecer por longo tempo em suas terras e cultivá-las. Para tanto foi realizado o movimento "GAT", que originalmente são as iniciais de "Give and Take", mas no Brasil foram utilizadas como "Gozar a Terra" (Burajiru ni okeru nihonjin hattenn shi, 1953). Outro exemplo, é a fundação da "Cooperativa Agrícola de Cotia - C.A.C." em 1927. Esta cooperativa foi fundada com o objetivo de proteger os agricultores japoneses residentes na região de Cotia (São Paulo) contra a exploracão que os intermediários efetuavam ao negociar com os imigrantes. Exploração feita muitas vezes devido à deficiência do domínio da língua portuguesa por parte dos imigrantes japoneses.

Além destas cooperativas, verifica-se vários outros tipos de associações japonesas já na década de 1920. Em 1929 havia mais de 200 associações só no estado de São Paulo, e em 1953 o número cresce para mais de 400, entre associações culturais, provinciais, esportivas e outros (Burajiru ni okeru nihonjin hattenn shi, 1953).

Estas cooperativas e associações tinham como objetivo além de reunir os imigrantes japoneses e nikkeis em grupos, servir de intermediário entre o grupo étnico nipo-brasileiro e a sociedade brasileira e também servir de suporte para a ascensão dos mesmos no Brasil. Por exemplo, tanto na parte econômica ou política, os primeiros fregueses ou os primeiros a apoiarem candidatos nikkeis a cargos políticos, geralmente eram os próprios nikkeis.

Atualmente, ainda pode-se verificar inúmeras associacões nipo-brasileiras no Brasil, e muitos jovens nikkeis continuam a frequentá-las, apesar de não possuirem mais o problema de idioma e falta de informações sobre a sociedade brasileira como ocorrera com os primeiros imigrantes.

\section{Ser "brasileiro" no Japão}

Atualmente, a vinda dos nikkeis brasileiros para o Japão como dekasseguis, proporciona aos nikkeis a oportunidade de conhecerem o Japão atual e compará-lo com o "Japão" que lhes foi ensinado no Brasil. Assim, considerando esta nova fase na história da imigracão japonesa para o Brasil, podemos dizer que o nikkei brasileiro encontra-se atualmente no estágio posterior ao da "estratégia de permanência no Brasil", elaborada por Maeyama.

Com essas mudanças de ambiente em que os nikkeis passam, ou seja desde a época dos primeiros imigrantes japoneses ao Brasil até os atuais nikkeis que vêm ao Japão, pode-se traçar um perfil da identidade dos nikkeis, considerando a teoria de Bourdieu, onde diz que o "capital cultural" é formado conforme as influências do ambiente em que o agente se encontra, e pelo conceito de "habitus", que diz que um agente absorve inconscientemente determinados costumes, valores e atitudes em determinados ambientes, os quais passam a influenciar diretamente em sua consciência e atividades. 
Analisando os fatos históricos, desde o início da imigração japonesa no Brasil, foram formadas inúmeras associações nipônicas, independentemente se serem em área urbana ou rural. Esta tradição se mantém ainda nos dias atuais, fator de grande importância para o fortalecimento da identidade nikkei e para a transmissão e preservação dos valores culturais nipônicos. Esta identificação do nikkei com o "japonês" é devido às influências educacionais e culturais existentes dentro do grupo étnico nikkei no Brasil. Frisamos aqui, que esta identificação não significa que o nikkei não se considere brasileiro, mas que o nikkei é um brasileiro que possui uma identidade étnica "japonesa".

Quando o nikkei vem ao Japão, conhece a realidade do país e a sua cultura "japonesa" adquirida no Brasil é rejeitada, ele tende a rejeitar sua identidade étnica como "japonês". Devido ao ambiente em que é colocado, num ambiente de brasileiros tanto no trabalho como na moradia, o nikkei tende a identificar-se como um brasileiro. Após os primeiros choques culturais, "aprendem" a conviver com a realidade cultural e social do país, enfrentando barreiras como discriminação racial, social e cultural.

No caso dos nikkeis adultos no Japão, estes tendem a preservar a cultura e costumes brasileiros no seu dia-a-dia. Mas as crianças, que moram no Japão e mal conhecem o Brasil, tendem a adaptar-se com maior facilidade à cultura e costumes japoneses.

No ambiente em que as crianças brasileiras se encontram no Japão, salvo as que frequentam escolas brasileiras, elas usam predominantemente a língua japonesa diariamente e estão imersas na cultura japonesa (escola, amigos, etc.). Estas crianças têm o Brasil apenas como o país de origem, distante da sua realidade cotidiana. A tendência é que com o passar do tempo, sua identidade como "brasileira" se transfira para a identidade japonesa, apesar dos adultos brasileiros manterem a cultura e identidade brasileira ativa no Japão. Também já vemos jovens brasileiros que ingressaram em cursos superiores no Japão e pretendem viver definitivamente no país, pois para eles o Brasil é o país dos seus pais, que conhecem apenas através de informações que lhes são transmitidas indiretamente, como língua portuguesa falada em casa, comida brasileira, amigos brasileiros, etc. (ISHIKAWA, 2007).

Aqui, podemos dizer que a tendência das crianças brasileiras é de se inserirem na sociedade japonesa e manterem a cultura e costumes do Brasil na sua memória, apenas como um símbolo de sua origem, como ocorreu entre os filhos dos imigrantes japoneses no Brasil. A imagem do Brasil que predomina no Japão são os aspectos negativos, como pobreza, criminalidade e um país ainda em desenvolvimento (atrasado). Alguns pontos positivos mostrados na mídia japonesa são restritos ao futebol, floretas da Amazônia, animais exóticos e o carnaval. Devido a predominância da imagem negativa do Brasil no Japão, é muito difícil uma criança ou jovem brasileiro assumir a identidade brasileira perante a sociedade japonesa, uma vez que muitos deles nem conhecem pessoalmente o Brasil. Quanto aos adultos brasileiros no Japão, estes costumam relacionar a cultura brasileira como um povo alegre, amigável, e com muito calor humano, ou seja qualidades que eles consideram contrárias aos japoneses (do Japão), onde são frequentemente considerados frios e preconceituosos. 


\section{Experiências de jovens brasileiros no Japão}

É muito comum ouvirmos relatos de jovens brasileiros que não querem ser chamados de brasileiros, que não querem que seus pais falem português em frente dos amigos japoneses, ou até mesmo escondem seus nomes em português, utilizando apenas o nome japonês na escola. Tudo isso, por medo de serem alvo de maus-tratos ou discriminação, apenas por serem brasileiros. Aqui, serão apresentados relatos de seis jovens brasileiros que frequentam ou frequentaram universidades japonesas. As entrevistas foram feitas individualmente, entre 2008 e 2015. A língua utilizada na entrevista foi escolhida pelo próprio jovem, o português, o japonês ou às vezes misturando as duas línguas.

- Pedro: Entrevista em japonês.

Até a universidade não utilizava o nome "Pedro", apenas Suzuki Taro. Pedro nasceu no Brasil e veio ao Japão ainda pequeno, e sempre estudou em escola japonesa. $\mathrm{Na}$ escola, não gostava que o chamassem de Pedro, pois isso era razão para ser tratado como uma pessoa diferente e ser alvo de comentários maliciosos. Só passou a usar o nome em português após ingressar na universidade, pois entre os colegas de turma, o fato de ter um nome estrangeiro era razão de apreciamento e elogios.

- Tereza: Entrevista em português.

Tereza alisava os cabelos todas as manhãs para se parecer mais japonesa. Tereza é filha de mãe descendente de japoneses e pai descendente de africano e português. Os cabelos de Tereza são castanhos e encaracolados, e isso a incomodava quando comparados aos cabelos de suas amigas japonesas, que eram lisos e pretos. Por isso, Tereza acordava às cinco e meia todas as manhãs para alisar os cabelos antes de ir para aula que começava às oito horas. Mesmo na universidade, apesar de não alisar os cabelos todos os dias, sempre está com o cabelo preso.

Tereza diz que passou praticamente 2 anos, entre 12 e 13 anos sendo literalmente ignorada pelos colegas de classe, por isso sempre estava sozinha na escola. Neste período chegou a emagrecer 5 quilos pelo estresse, mas com o apoio dos pais não desistiu da escola e enfrentou a discriminação e dificuldades na escola. Quando ingressou no ensino médio, em um curso de estudos internacionais, onde havia ênfase no ensino da língua inglesa, todos os colegas passaram a ter interesse na sua história e experiência como brasileira. Também a sua fluência do inglês a ajudaram a manter sua autoestima. Hoje, graduada por uma universidade japonesa, trabalha em uma empresa multinacional, fora do Japão, onde sua fluência nas línguas japonesa, inglesa e portuguesa foi fator chave para sua contratação.

- Bianca: Entrevista em português.

Nasceu no Japão e sempre estudou em escolas japonesas. Sua matéria preferida era história (do Japão). Apesar de sua mãe não ter descendência japonesa e Bianca ter 
os cabelos encaracolados, diz nunca ter sofrido maus-tratos nas escolas ou na sua vida cotidiana. Sempre estudou em escola japonesa, e no ensino médio resolveu prosseguir para uma escolar particular, em um curso internacional, onde o inglês era disciplina obrigatória. Durante o curso, participou de um intercâmbio nos Estados Unidos, onde estudou durante 1 ano em uma escola pública local. Lá, se dizia japonesa, "from Japan", e todos a aceitavam, pois nos Estados Unidos todos têm aparência diversa, fato que não é relacionado com a nacionalidade. Por isso, ela dizia que era do Japão. Retornando ao Japão, ingressou numa universidade japonesa em Tóquio, que oferece curso com aulas em inglês.

No Japão, diz que é brasileira, apesar de ter nascido no Japão, principalmente por sua aparência ser de mestiça, todos a tratam como estrangeira. Mas agora que mora em Tóquio, quando perguntam de onde ela é, ela diz "sou de Aichi-ken". Aí, começam as infinitas perguntas, em que Bianca tem que explicar que é nascida no Japão, mas que os pais são brasileiros, e toda sua história de vida.

Sobre sua identidade, ela diz que não é nem japonesa nem brasileira, ela é "Bianca". Ela se sente diferente dos japoneses e ao mesmo tempo diferente dos brasileiros. Aponta alguns pontos positivos e negativos dos japoneses e brasileiros. Como ponto negativo dos brasileiros, ela acha que deveriam se adaptar mais a sociedade japonesa. Muitos brasileiros querem viver no Japão como se estivessem no Brasil, e ela não concorda com isso. Mas pessoalmente acha os que os brasileiros são mais calorosos, com uma mente mais aberta do que a dos japoneses.

Com relação aos japoneses, acha que são muito fechados, mas por outro lado, todos obedecem as regras, e isso contribui para que tudo funcione no Japão.

- Roberto: Entrevista em português, apesar da sua língua preferida ser o japonês. Nasceu no Brasil, Rio de Janeiro, e veio ao Japão com 5 anos de idade.

Foi para creche brasileira, e depois para escola japonesa (primário). Frequentava aulas de português aos sábados, com professor particular. Ia pela insistência da mãe, e também porque muitos amigos iam, mas não gostava.

Possui a nacionalidade brasileira e no momento não pensa em se naturalizar, pois diz que não tem nenhum problema com a nacionalidade brasileira. Mas ele não sabia que poderia manter a dupla nacionalidade mesmo após a naturalização. Outra razão, diz que tem orgulho de ser brasileiro, por isso não pensa em se naturalizar.

No final do ensino fundamental, os professores incentivaram o Roberto a estudar e continuar os estudos no ensino médio, dizendo que ele tinha capacidade. Muitos brasileiros não tinham interesse em estudar, dizendo que não adiantava e que começariam a trabalhar em vez de prosseguir com os estudos. Alguns já são casados e têm filhos, e trabalham em fábricas como operário. Hoje, estes amigos dizem que o Roberto tem sorte em ainda ser estudante. Roberto ri, e diz que os amigos não fazem ideia das dificuldades que ele passou. Por exigência da mãe, em casa fala apenas em português. Mas com o irmão fala em japonês. Sua primeira língua é o japonês, depois o 
inglês, e por último o português. Muitas vezes traduz do inglês para o português. Acha que tem mais vocabulário em inglês do que em português.

Roberto diz ser brasileiro, mas diferente dos brasileiros e também dos nikkeis no Brasil. Sente-se mais japonês agora, mas também diferente dos japoneses. Os japoneses são mais fechados. Teve namoradas japonesas e nikkeis que moram no Japão. Para casar, alguém que possa acompanhá-lo, no Brasil ou no Japão.

Não pensa em retornar ao Brasil, pois como não tem estudo no Brasil acha muito difícil encontrar trabalho lá. Mas sua mãe quer que ele volte um dia ao Brasil, por isso não descarta esta possibilidade. Hoje, graduado por uma universidade japonesa, trabalha em uma empresa local na área de vendas.

- Angela: Entrevista, no início em português, depois em japonês.

Veio ao Japão com 1 ano e meio e ficou até os 10 anos. No Japão frequentou escola japonesa antes de retornor ao Brasil. Lá permaneceu por 2 anos, quando frequentou a $5^{\mathrm{a}}$ e $6^{\mathrm{a}}$ séries. Voltando ao Japão, estudou em uma escola brasileira por 2 anos, $6^{\mathrm{a}}$ a $8^{\mathrm{a}}$ série, e depois se transferiu para uma escola japonesa. No Japão há um tipo de vestibular para o ensino médio, e quando Angela escolheu uma escola pública considerada uma das melhores da cidade, seus professores a aconselharam a mudar de ideia e prestar o vestibular em uma escola "mais fácil". Porém ela não mudou a decisão, e para a surpresa de seus professores, foi aprovada na escola que havia escolhido, a "mais difícil". Angela teve outras experiências ruins na escola japonesa. Teve problemas para fazer a sua transferência para a escola japonesa, pois o diretor não queria aceitar sua documentação. Angela acha que para o diretor ela seria outro "problema" para a escola e professores. Mas depois de muita insistência e perseverança da mãe, foi aceita.

No início, naturalmente suas notas eram muito baixas, como em uma prova de japonês que valia 50 pontos, tirou 5. Mas o que mais a irritava, era que a professora lhe dizia que 5 estava bom, e que ela tinha estudado o suficiente. Para Angela isso era um insulto como se os estrangeiros não fossem capazes de aprender o japonês. Mas essa raiva foi um incentivo para que estudasse mais, e em pouco tempo suas notas melhoraram.

$\mathrm{Na}$ escola Angela sempre tentava se aproximar das outras japonesas, o que não foi fácil, pois com frequência era ignorada pelas colegas de classe. Porém, após participar e vencer uma oratória de inglês, as colegas e os próprios professores passaram a respeitála mais.

$\mathrm{Na}$ escola sempre usou seu nome apenas em japonês, ou seja Angela era usado apenas em casa. Como seus pais são ambos nikkeis, Angela se passava por japonesa sem problemas. Hoje, universitária, se sente incomodada quando chamada de brasileira, apesar de que na universidade seu conhecimento do português é fator para elogios e até inveja por parte de colegas japoneses.

Com 21 anos ela se sente mais confiante com a língua japonesa, tanto que durante a entrevista que começou em português, logo mudou para japonês, pois para Angela era 
mais fácil explicar seus sentimentos em japonês do que em português. Após ingresso na universidade, passou 1 ano nos Estados Unidos, onde melhorou sua proficiência do inglês.

Quanto ao casamento, diz que prefere nikkei brasileiro, residente no Japão. Não quer casar-se com japonês, mas também se sente muito diferente dos nikkeis do Brasil. Para ela, os nikkeis do Brasil são "brasileiros" demais. Quanto a sua identidade, se sente diferente dos japoneses, mas também diferente dos brasileiros, ou seja ela diz que é "nikkeijin".

- Sonia: Entrevista em japonês.

Sonia é mestiça, filha de pai nikkei e mãe não-descendente de japonês, e desde pequena sempre frequentou escola japonesa, por isso sempre dominou o japonês mais do que o português, que só falava dentro de casa. Seu pai sempre a incentivou, ou segundo Sonia sempre a obrigou a estudar, e sempre dizia que ir para a universidade era uma obrigação.

Nas escolas, teve várias experiências de discriminação, talvez pela sua aparência, mas por outro lado sempre teve amigos japoneses que a apoiavam e a ajudavam. Até seu ingresso na universidade, ela nunca teve amigos brasileiros, isso por sua escolha, pois sempre evitava o relacionamento com brasileiros, mesmo com os que frequentavam a mesma escola. Só na universidade, que quando chamada de brasileira não se ofendida, pois agora isso não significava discriminação, mas uma qualificação por entender e falar um pouco de português.

Mas quando lhe perguntam sobre o Brasil ou se ela sabe cozinhar comida brasileira e ela diz que não, os amigos japoneses ficam "decepcionados". Para Sonia, que nunca morou no Brasil, não conhecer o Brasil é uma coisa normal.

Quando Sonia resolveu prestar o vestibular para a universidade, estudou muito, pois sabia que não queria trabalhar em fábricas, e a única maneira de conseguir um emprego mais "decente" seria com um diploma universitário. Quanto ao casamento, diz que prefere casar-se com um japonês, mas um japonês que conheça o Brasil.

Sonia teve uma experiência que a fez pensar mais sobre a sua nacionalidade. Ainda no ensino médio, teve que desistir de uma viagem para Austrália com sua turma de classe, pois devido a sua nacionalidade brasileira, não daria tempo para tirar o visto de turista até a data da viagem. Na época, nem mesmo os professores sabiam da necessidade de visto para brasileiros, uma vez que para os japoneses não é necessário tirar o visto de turista para a Austrália. Após este episódio, pensou em se naturalizar japonesa, pois queria ser exatamente como os outros japoneses, mas hoje prefere manter sua nacionalidade brasileira porque tem orgulho de ser brasileira.

Atualmente Sonia trabalha em uma empresa japonesa, onde seu conhecimento de português a ajuda no seu trabalho. 


\section{Conclusão}

Ao analisar os nikkeis no Brasil e no Japão, verificamos que a identificação do nikkei com o grupo étnico nipo-brasileiro é um resultado de fatores relativos ao ambiente em que é colocado, como famílias, local de trabalho e moradia.

No Brasil, os nikkeis recebem as influências referentes ao "Japão" e o "japonês" no seu ambiente cotidiano (família, associações nipo-brasileiras), onde "Japão" e "japonês" possuem uma conotação simbólica positiva, ou seja estes termos referem-se a qualidades como honestos, trabalhadores e esforçados, aos quais o nikkei se identifica. Esta identificação pode aqui ser considerado como um capital cultural pertencente ao nikkei.

Por exemplo, o capital cultural comum entre os nikkeis no Brasil são os fatos de terem como ancestrais os imigrantes japoneses, de viverem em um ambiente com influências nipônicas e possuírem a consciência de um "nikkei", o que automaticamente significa ser um "japonês honesto e trabalhador". Como resultado este capital cultural influencia inconscientemente e/ou conscientemente nas atividades e maneira de pensar de muitos nikkeis brasileiros.

Analisando os fatos históricos, desde o início da imigração japonesa no Brasil, foram formados inúmeras associações nipônicas, independente se em área urbana ou rural. Esta tradição se mantém ainda nos dias atuais, fator de grande importância para o fortalecimento da identidade nikkei e para a transmissão e preservação dos valores culturais nipônicos. Porém, esta identificação não significa que o nikkei não se considere brasileiro, mas um brasileiro que possui uma identidade étnica "japonesa".

Quando o nikkei vem ao Japão e conhece a realidade do país, primeiramente ele tende a rejeitar sua identidade étnica como "japonês", e devido ao ambiente em que é colocado, ou seja num ambiente de trabalho e moradia com muitos brasileiros, o nikkei tende a identificar-se como um brasileiro, porém um "nikkei-brasileiro" que é diferente dos outros brasileiros por ser nikkei, e ao mesmo tempo diferente do japonês por ser brasileiro.

Os jovens brasileiros que vivem no Japão atualmente, passam por experiências semelhantes das que os nikkeis tiveram no Brasil. Apesar de estarem num ambiente japonês, onde a língua predominante é o japonês, sempre são considerados como brasileiros, na maioria das vezes com conotação negativa. A cultura brasileira e língua portuguesa são passadas para os filhos predominantemente num ambiente familiar, por isso o jovem nikkei acaba se familiarizando mais com a cultura japonesa e se tornando mais fluente na língua japonesa. E já vemos, como no caso de jovens citados acima, que se sentem mais confiantes quando falam em japonês. Ou seja, os jovens nikkeis brasileiros, muitos nascidos no Japão, agora percorrem o trajeto inverso dos pais, quando ser "brasileiro" se torna a sua identidade étnica e simbólica. 


\section{Referências Bibliográficas}

BOURDIEU, Pierre. Distinction: A Social Critique of the Judgement of Tast. Tradução Richard Nice. Cambridge, Massachusetts: Harvard University Press, 1984. Tradução de: La Distinction: Critique sociale du jugement, 1979.

BURAJIRU NI OKERU NIHONJIN HATTEN SHI KANKOU IINNKAI Burajiru ni okeru nihonjin hatten shi, ge, Tokyo: 1953.

CENTRO DE ESTUDOS NIPO-BRASILEIROS DE SÃO PAULO, Burajiru ni okeru nikkei jinko chousa houkokusho (Levantamento da população dos nikkeis no Brasil). São Paulo: 1988.

FUJITA, Stephen; O'BRIEN, David. Japanese American Ethnicity: The perspective of Community. Seattle and London: University of Washington Press, 1991.

GLAZER, Nathan; MOYNIHAN, Daniel. Ethnicity: Theory and Experience. Cambridge, Massashusetts, and London: Harvard University Press, 1975.

ISHIKAWA, Eunice Akemi. Condições das Crianças e Jovens Brasileiros no Japão e suas Perspectivas. In: KISHIMOTO, Tizuko; DERMATINI, Zeila (orgs.) Educação e Cultura: Brasil e Japão. São Paulo: Editora da Universidade de São Paulo, 2012. pp. 223-238.

ISHIKAWA, Eunice Akemi. Shingaku wo tahashita Nikkei burajirujin no wakamono no gakkou keiken. In: TAKAHASHI, Miyajima (org.) Gaikokujin jidou/seito no shuugaku mondai no kazoku haikei to shuugakushien network no kenkyu. Tokyo: Kagaku Kenkyûhi (Ministério da Educação, Cultura, Esporte, Ciência e Tecnologia do Japão), 2007. pp. 75-87.

JAPAN IMMIGRATION ASSOCIATION. Zairyu gaikokujin toukei. Tokyo: Ministry of Justice of Japan, 1986-2015.

MAEYAMA, Takashi. Ethnicity to burajiru nikkeijin. Tokyo: Ochanomizu Shogo, 1996.

MAEYAMA, Takashi. Imin no Nihon kaiki undou. Tokyo: NKH Books, 1982.

MIYAJIMA, Takashi. Bunkateki saisensan no shakaigaku. Tokyo: Fujihara Shoten, 1994.

REITZ, Jeffrey. The Survival of Ethnic Groups. Toronto: McGraw-Hill Ryerson Limited, 1980.

SAITO, Hiroshi; MAEYAMA, Takashi. Assimilação e Integração dos Japoneses no Brasil. São Paulo: Vozes/Editora da Universidade de São Paulo, 1973. 